\title{
An Optimized Data Management Model for Maternal Mortality in Bayelsa State
}

\author{
Ide, Mercy A Mathias Daniel Anireh V. I. E. \\ Department of Computer Science, Rivers State University, Port Harcourt, Nigeria
}

\begin{abstract}
Maternal Mortality Rate (MMR) is the quantity of maternal deaths in a given duration per 100,000 of reproductive aged (15-49) women. This amounts to both the obstetric risk and the rate of recurrence at which women are unprotected to this risk. In Bayelsa State, the maternal mortality has high rates. The driving reasons for death are related with hypertensive disorder, severe bleeding, infection and other complications of delivery that could be avoided. This research aims to develop a maternal mortality system using Data mining techniques; estimation of maternal mortality rate in Otuasega Cottage Hospital in Ogbia Local Government Area in Bayelsa State was carried out by analyzing the causes of death during pregnancy; Naive Bayes was used in Bayes Server to classify Hypertensive diseases into preeclampsia and gestational, identifying the symptoms and risk factors. Among other causes of maternal death evaluated, Hypertensive disease was the highest cause of maternal death in Bayelsa State between 2012 to 2018. We developed a Bayesian maternal mortality estimation model, that catches increasing speeds and deceleration in the rate of progress in the maternal death rate. Result shows that the trend was as low as 2 maternal deaths in every 202 live births in 2012 but increased to 12 per 210 live births in 2016. The maternal mortality rate continued its upward trend and increased to 14 deaths per 172 live births in the year 2018. Maternal mortality rate which was very low have increased significantly, and most death were caused by Hypertensive, followed by bleeding, complications and little of infections.
\end{abstract}

Keywords: Naïve Bayes, Bayesian Estimation Model, Maternal Mortality

DOI: $10.7176 / \mathrm{CEIS} / 10-5-02$

Publication date:June $30^{\text {th }} 2019$

\section{Introduction}

Universally, childbirth is an occasion that pulls in festivity; however, this is not so for some women who experience childbirth as torment and catastrophe that may end in death. Nigeria has a population of 140 million individuals with women of youngster bearing age establishing around 31 million and kids under five years old comprising 28 million (National Bureau of statistics, 2010). Women of child bearing age and kids under five years old thusly comprise a noteworthy level of the country's population. Nigeria, which comprises only $1 \%$ of the total population, represents $10 \%$ of the world's maternal and under-five death rates. Nigeria positions second on the planet, after India, in the size of maternal mortality with the rate of 800 deaths for each 100000 live births. Till date, Nigeria is second on maternal death rate on the planet with around 144 young ladies and women dying on consistently from intricacy of pregnancy and childbirth. 1 in each 18 women die conceiving an offspring contrasted with 1 of every 4800 in the US (Pitterson, 2010). Presently, Nigeria ranks 7th in the world, and as a fast growing country, its population is over 200 million (Akinyemi, 2018). Government can improve the health facilities to decrease maternal mortality if a control system is set up to report death rate in the nation. As indicated by an examination, health facilities and human health possessions, (for example, prepared medical clinics and well trained personnel) are progressively profitable for rustic networks (Jennet et al., 2015), along these lines, the conveyance of these services remotely using accessible technology could help to level up the unequal access to health services. Electronic health records, risk assessment systems, and remote control are just some examples of how technology can be applied in the healthcare field. This gigantic measure of information surpasses the capacity of traditional techniques to examine and look for fascinating examples and data that is hidden in them. Hence, new strategies and tools for finding helpful data in these information stores are ending up and the more demanding. In this thesis, a maternal mortality rate registry operating in Bayelsa State is used as the data source. This paper proposes a Naïve and Bayesian model that uses Data Mining (DM) techniques capable for operating in a data set to extract patterns and assist in knowledge discovery. Identifying risk factors of hypertensive disease that complicate pregnancy. Its impact is in a meaningful reduction of death of pregnant women. Bayesian maternal mortality estimation model is used to produce estimates of maternal mortality rate based on the available data.

\section{Related Literature}

Maternal Mortality Rate (MMR) is the quantity of maternal deaths in a given duration per 100,000 of reproductive aged (15-49) women. This amounts to both the obstetric risk and the rate of recurrence at which women are unprotected to this risk (Graham et al, 2008). The meaning of maternal mortality has transformed after some time, that brought about irregularities in estimations and recent concerns to regulate declines in 
maternal mortality. What's more, the presentation of the meaning of "pregnancy related death" rather than "maternal demise" has been a wellspring of estimation variety. For example, an investigation from Bangladesh revealed 15\% more pregnancy-related death contrasted with maternal death (Hill et al., 2006). The blend of the three predominant direct therapeutic reasons for maternal death (dying, disease and hypertensive illnesses) instigated the biggest extent of MMR per 100,000 live births (Khan et al., 2006). (Han \& Kamber, 2006) characterized data mining as the way toward finding intriguing learning from a lot of data put away in knowledgebase, data distribution centers, or other data storehouses. (Witten et al., 2005) characterized data mining as the way toward separating verifiable, already obscure and conceivably valuable data from data. (Hand, et al., 2011) characterized data mining as the investigation of observational informational index to discover unsuspected connections and to condense the data in novel ways that are both justifiable and helpful to the data proprietor. (Gandhi \& Singh, 2015) proposed way to predict heart disease using different data mining techniques. Author suggests classification methods for prediction of heart diseases using decision tree representation, neural network. (Shegaw, 2012) anticipates tyke mortality designs on the use of data mining innovation. An informational collection adding together 1,100 records of kids was utilized to manufacture and test both neural system and choice tree models. So as to assemble models that could foresee the danger of tyke mortality, a few models were worked by utilizing both neural system and choice tree methodologies. The superlative accomplishment of neural system model and choice tree classifier were then picked and assessed utilizing ten beforehand inconspicuous data of kids. (Arvind \& Gupta, 2012) talked about how Data mining contributed with essential advantages to the blood donation center division. J48 calculation and WEKA device have been utilized for the total research work. Characterization rules executed well in the grouping of blood givers, whose exactness rate achieved 89.9\%. (Elias, 2014) examined the AIDS is the ailment brought about by HIV, which debilitates the organization's insusceptible framework until it can never again fend off the straightforward contaminations that most solid individuals' invulnerable framework can stand up to. From the earlier calculation it is utilized to find affiliation rules. WEKA 3.6 is utilized as the data mining apparatus to actualize the Algorithms. The J48 classifier accomplishes order with $81.8 \%$ exactness in foreseeing the HIV status.

\section{Naïve Bayes Classifier for Maternal Mortality}

The Naïve Bayes classifier is appropriate in health care when there is a set of attributes that represents each risk factor. Every single one of these attributes occurred in a particular hypertensive disorder as shown in Figure 1. This classifier based on Bayes theorem is used to determine the probability of each hypertensive disease from symptoms never seen based on trained examples.

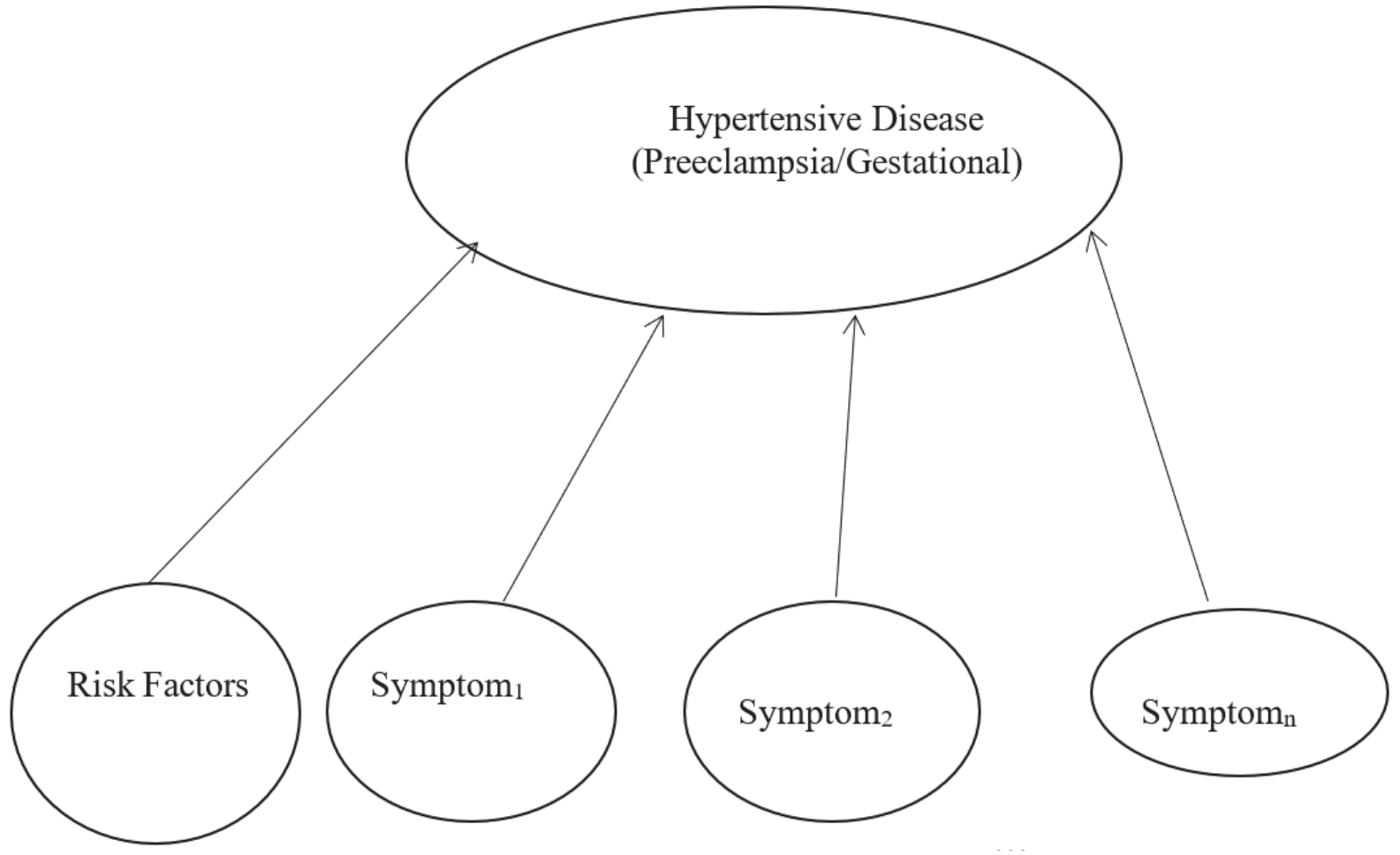

Figure 1: Naïve Bayes Classifier

Risk factors associated with Preeclampsia and Gestational Hypertensive are age (under 20), age (40 above), first pregnancy, multiple fetuses, diabetes, overweight before pregnancy, preexisting high blood pressure and 
kidney disease.

Symptoms for Preeclampsia and Gestational Hypertensive are: severe headache, swelling, abdominal pain, dizziness, excessive vomiting and blurred vision.

For instance;

Let $\left(a_{1}, a_{2}, \ldots, a_{n}\right)$ represent set of hypertensive disorder

$\mathrm{X}_{\mathrm{MAP}}=\operatorname{argmax}_{X_{j \in X}} \frac{P\left(a_{1}, a_{2}, \ldots, a_{n} \mid X_{j}\right) P\left(X_{j}\right)}{P\left(a_{1}, a_{2}, \ldots, a_{n}\right)}$

Where,

$\mathrm{X}_{\mathrm{j}}$ is the data not seen

$\mathrm{X}_{\mathrm{MAP}}$ is the case with maximum posteriori probability

The probability of observed $\left(a_{1}, a_{2}, \ldots, a_{n}\right)$ is precisely the product of the probabilities associated with each attribute

$\mathrm{P}\left(\mathrm{a}_{1}, \mathrm{a}_{2}, \ldots, \mathrm{a}_{\mathrm{n}} \mid \mathrm{X}_{\mathrm{j}}\right)=\prod_{i} P\left(a_{i} \mid X_{j}\right)$

\section{Bayesian Maternal Mortality Model}

Modelling of maternal mortality is required to produce estimates based on the available data from Otuasega Cottage Hospital, Bayelsa State Ogbia Town.

Estimated maternal mortality rate:

$X_{b, t 1, t 2}$ is the main quality to be estimated, which is the number of maternal deaths for Bayelsa State $b$ for any period $\left(\mathrm{t}_{1} ; \mathrm{t}_{2}\right)$.

$X_{b, t}=X_{b, t, t+1}$ is the number of maternal deaths in Bayelsa State $b$ in calendar year $t$.

$\mu_{b, t}$ is the final outcome of interest.

Bayelsa State-year estimates for births, deaths and HYPERTENSIVE deaths to women of reproductive ages are denoted by

B denotes birth

$\mathrm{D}$ denotes death

$\mathrm{D}^{\text {HYPER }}$ denotes HYPERTENSIVE deaths

$D_{b, t}=D_{b, t, t+1}$

i denotes the hospital of the observation (where data are gotten).

$\mathrm{s}_{\mathrm{i}}$ denotes the start date

$\mathrm{e}_{\mathrm{i}}$ denotes the end date

$t_{i}$ denotes to the calendar year of the midpoint of the observation period.

Therefore,

$X_{i}=X_{b[i], s[i], e[i]}$ and

$D_{i}=D_{b[i], s[i], e[i]}$

A model used to obtain estimates, in which maternal deaths were modelled as the sum of non-HYPERTENSIVE maternal deaths $X_{b, t}^{(\text {non-HYPER })}$ and

HYPERTENSIVE maternal deaths $\quad D_{b, t}^{(H Y P E R)}$

$\mathrm{X}_{\mathrm{b}, \mathrm{t}}=X_{b, t}^{(\text {non-HYPER })}+D_{b, t}^{(H Y P E R)}$

HYPERTENSIVE maternal deaths are deaths as a result of high blood pressure before or during delivery. The non-HYPERTENSIVE maternal deaths refer to maternal deaths due to Severe bleeding (mostly bleeding after childbirth), Infections (usually after childbirth), and other Complications from delivery.

\section{Modelling HYPERTENSIVE maternal deaths}

The modelling of HYPERTENSIVE maternal deaths $\quad D_{b, t}^{(H Y P E R)}$ is as follows:

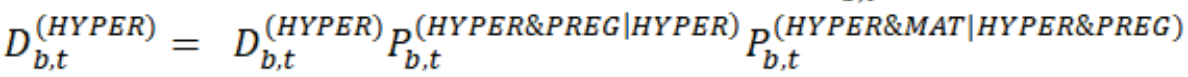

Where,

$D_{b, t}^{(H Y P E R)}$ is the number of HYPERTENSIVE deaths.

$P_{b, t}^{(H Y P E R \& P R E G \mid H Y P E R)}$ is the proportion of HYPERTENSIVE deaths that occurs during the maternal risk period.

$P_{b, t}^{(H Y P E R \& M A T \mid H Y P E R \& P R E G)}$ is the proportion of HYPERTENSIVE deaths among women during the 
maternal risk period that qualify as maternal because of some causal relationship with the pregnancy, delivery.

\section{Modelling non-HYPERTENSIVE maternal deaths}

The non-HYPERTENSIVE maternal deaths refer to maternal deaths due to Severe bleeding (mostly bleeding after childbirth), Infections (usually after childbirth), and other Complications from delivery.

$X_{b, t}^{(n o n-H Y P E R)} / D_{b, t}^{(n o n-H Y P E R)}$ is the proportion of non-HYPER maternal deaths among the total number of non-HYPER deaths of women of reproductive age.

$$
D_{b, t}^{(\text {non-HYPER })}=X_{b, t}^{(B L E E D I N G)}+X_{b, t}^{(I N F E C T I O N S)}+X_{b, t}^{(\text {COMPLICATIONS })}
$$

Maternal deaths are modelled for Bayelsa State-(2017-2018) as the sum of non-HYPERTENSIVE and HYPERTENSIVE maternal deaths.

\section{Results and Discussion}

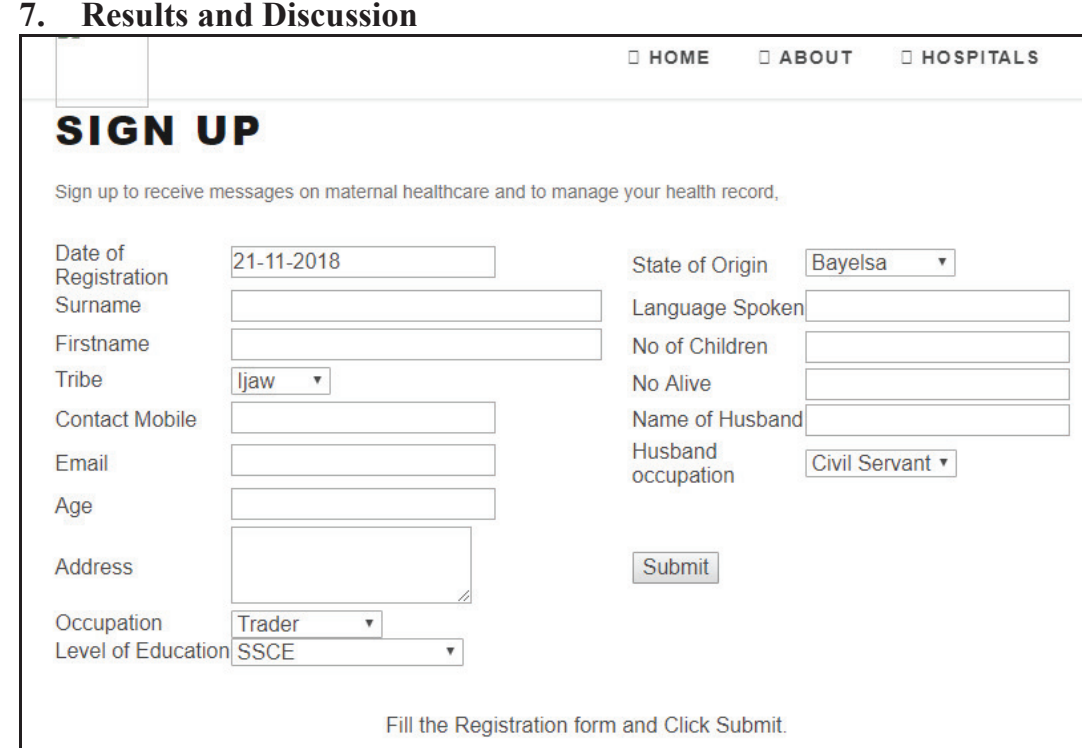

Figure 2 Mothers Registration Form

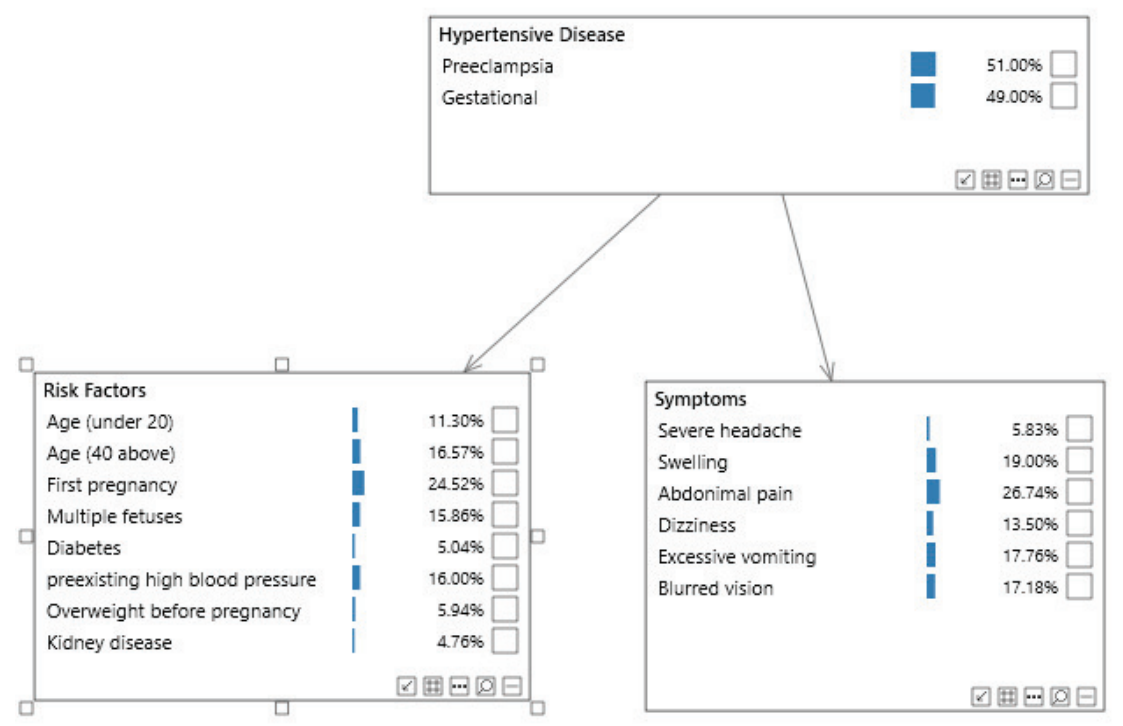

Figure 3: Hypertensive Disease Classification 
Table 1: Evidence of each Risk Factors Evidence of Age (under 20) Risk Factor

\begin{tabular}{|l|l|}
\hline $\begin{array}{l}\text { Hypertensive } \\
\text { Disease }\end{array}$ & S \\
\hline $\begin{array}{l}\text { Preeclampsia } \\
(70.13 \%)\end{array}$ & S \\
\hline Gestational $(29.87 \%)$ & S \\
\hline & A \\
\hline & D \\
\hline & E \\
& $(18$ \\
\hline & B \\
\hline
\end{tabular}

\begin{tabular}{|l|l} 
Symptoms & Peve headache (3.89\%) \\
Severe & Pre \\
Swelling (18.35\%) & Gomiting \\
\hline Abdominal pain (25.90\%) & \\
\hline Dizziness (12.98\%) & $\begin{array}{l}\text { Excessive } \\
(18.97 \%)\end{array}$ \\
\hline Blurred vision (19.90\%) & \\
\hline
\end{tabular}

Evidence of Preexisting High Blood Pressure Risk Factor

Evidence of Age (40 above) Risk Factor

\section{Disease}

Hypertensive

Preeclampsia

$(35.35 \%)$

Gestational (64.65\%)

Symptoms

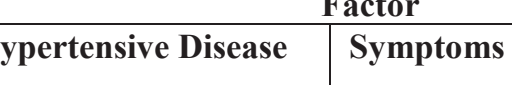

\begin{tabular}{|c|c|c|c|}
\hline Gestational (64.65\%) & Swelling (19.53\%) & Gestational (33.01\%) & Swelling $(18.46 \%)$ \\
\hline & Abdominal pain $(27.43 \%)$ & & Abdominal pain $(26.04 \%)$ \\
\hline & Dizziness $(13.92 \%)$ & & Dizziness $(13.06 \%)$ \\
\hline & $\begin{array}{ll}\text { Excessive } & \text { vomiting } \\
(16.77 \%) & \\
\end{array}$ & & Excessive vomiting $(18.77 \%)$ \\
\hline & Blurred vision (14.94\%) & & Blurred vision (19.46\%) \\
\hline \multicolumn{2}{|c|}{ Evidence of First Pregnancy Risk Factor } & \multicolumn{2}{|c|}{ Evidence of Kidney Disease Risk Factor } \\
\hline $\begin{array}{l}\text { Hypertensive } \\
\text { Disease }\end{array}$ & Symptoms & Hypertensive Disease & Symptoms \\
\hline $\begin{array}{l}\text { Preeclampsia } \\
(60.77 \%)\end{array}$ & Severe headache $(4.84 \%)$ & Preeclampsia $(42.47 \%)$ & Severe headache $(6.69 \%)$ \\
\hline Gestational (39.23\%) & Swelling(18.67\%) & Gestational $(57.53 \%)$ & Swelling (19.28\%) \\
\hline & Abdominal pain $(26.31 \%)$ & & Abdominal pain $(27.11 \%)$ \\
\hline & Dizziness $(13.23 \%)$ & & Dizziness $(13.73 \%)$ \\
\hline & $\begin{array}{ll}\text { Excessive } & \text { vomiting } \\
(18.38 \%) & \\
\end{array}$ & & Excessive vomiting (17.22\%) \\
\hline & Blurred vision (18.57\%) & & Blurred vision (15.96\%) \\
\hline \multicolumn{4}{|c|}{ Evidence of First Multiple Fetuses Risk Factor } \\
\hline $\begin{array}{l}\text { Hypertensive } \\
\text { Disease }\end{array}$ & Symptoms & & \\
\hline $\begin{array}{l}\text { Preeclampsia } \\
(47.62 \%)\end{array}$ & Severe headache $(6.17 \%)$ & & \\
\hline \multirow[t]{5}{*}{ Gestational (52.38\%) } & Swelling (19.11\%) & & \\
\hline & Abdominal pain $(26.89 \%)$ & & \\
\hline & Dizziness $(13.59 \%)$ & & \\
\hline & $\begin{array}{ll}\text { Excessive } & \text { vomiting } \\
(17.55 \%) & \end{array}$ & & \\
\hline & Blurred vision $(16.69 \%)$ & & \\
\hline \multicolumn{4}{|c|}{ Evidence of Diabetes Risk Factor } \\
\hline $\begin{array}{l}\text { Hypertensive } \\
\text { Disease }\end{array}$ & Symptoms & & \\
\hline $\begin{array}{l}\text { Preeclampsia } \\
(97.39 \%)\end{array}$ & Severe headache $(1.14 \%)$ & & \\
\hline Gestational $(2.62 \%)$ & Swelling $(17.43 \%)$ & & \\
\hline
\end{tabular}


Table 2: Maternal Mortality

\begin{tabular}{|r|r|r|l|r|}
\hline \multicolumn{1}{|l|}{ YEAR } & BIRTHS & MATERNAL DEATHS & CAUSE OF DEATH & MATERNAL MORTALITY RATE \\
\hline 2012 & 202 & 2 & HBP & 4.21 \\
\hline 2013 & 178 & 5 & HBP & 7.43 \\
\hline 2014 & 219 & 6 & HBP AND COMPLICATIONS & 11.78 \\
\hline 2015 & 210 & 11 & HBP AND BLEEDING & 18.91 \\
\hline 2016 & 171 & 12 & BLEEDING AND COMPLICATIONS & 19.05 \\
\hline 2017 & 146 & 11 & INFECTIONS & 18.91 \\
\hline 2018 & 172 & 14 & COMPLICATIONS & 22.82 \\
\hline Total & 1096 & 61 & & \\
\hline
\end{tabular}

35

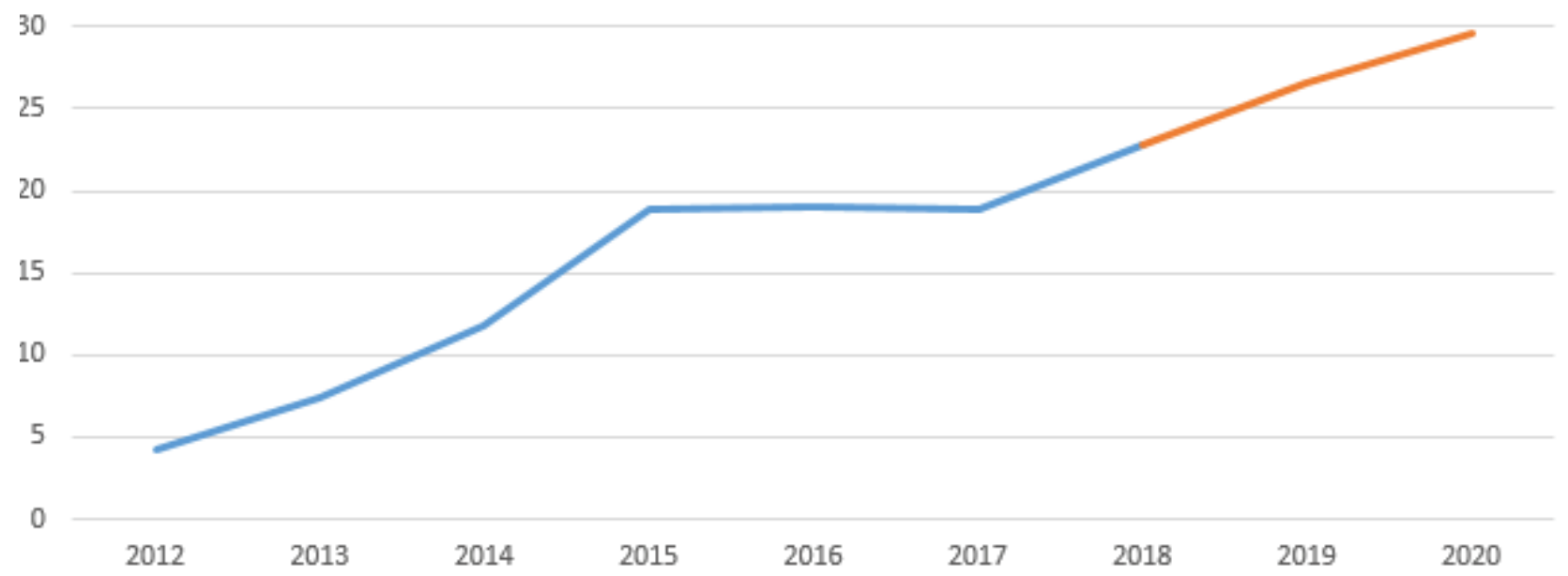

MATERNAL MORTALITY RATE _ Forecast(MATERNAL MORTALITY RATE)

Figure 4: Maternal Mortality Rate

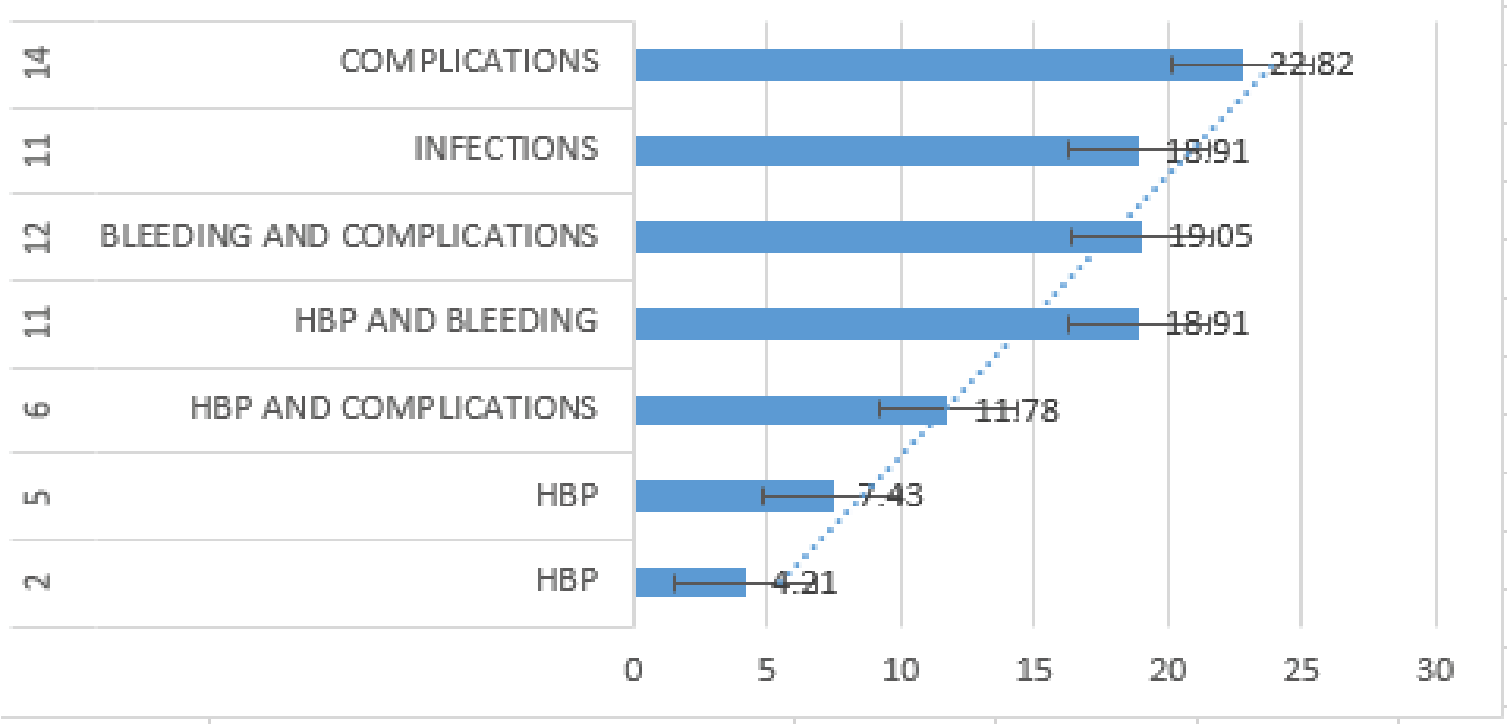

Figure 5: Cause of death

A web-based application that monitors maternal mortality in Bayselsa State using PHP and BMat estimates for Otuasega Cottage Hospital, Bayelsa State was done using Bayes Server. The BMat estimates for Otuasega Cottage Hospital, Bayelsa State are given by the adjusted maternal mortality data for a period of 7years (2012- 
2018). The maternal mortality system software meets user requirement relating to entering patient data as shown in Figure 2. Hypertensive disease was classified using Bayes Server. Classification of Hypertensive disease was based on Preeclampsia and Gestational Hypertensive. Risk factors associated with Preeclampsia and Gestational Hypertensive are age (under 20), age (40 above), first pregnancy, multiple fetuses, diabetes, overweight before pregnancy, preexisting high blood pressure and kidney disease. Symptoms for Preeclampsia and Gestational Hypertensive are: severe headache, swelling, abdominal pain, dizziness, excessive vomiting and blurred vision. Preeclampsia hypertensive has a probability of $51.00 \%$ and Gestational hypertensive of $49.00 \%$, each attributes has a certain probability. In risk factors, first pregnancy has the highest probability of $24.52 \%$. In symptoms, abdominal pain has the highest probability of $26.74 \%$. Hypertensive disease node, risk factors node and symptoms node are discrete while range node is continuous as shown in Figure 3. The evidence of each risk factors affects the probability value of hypertensive disease and symptoms as shown in Table 4.1. Calculating the evidence of the risk factors; evidence of age (under 20) shown that most women under 20 of age have preeclampsia with $70.13 \%$ and blurred vision symptom of $19.90 \%$, evidence of age (40 above) shown that most women 40 years and above have Gestational Hypertensive disease with $64.65 \%$ and abdominal pain $27.43 \%$. Estimated maternal mortality rate in Otuasega Cottage Hospital in Ogbia Local Government Area in Bayelsa State as shown in Table 2, on maternal mortality we observed that the trend was as low as 2 maternal deaths in every 202 live births in 2012 but increased to 12 per 210 live births in 2016. The maternal mortality rate continued its upward trend and increased to 14 deaths per 172 live births in the year 2018. Figure 4 shows that maternal mortality rate which was very low, increased significantly, and most death were caused by Hypertensive disorder, followed by bleeding and complications and little of infections as shown in Figure 5.

\section{Conclusion}

Maternal deaths are fueled by poor utilization of healthcare facilities and services in Bayelsa State. As a result of the increase in Maternal Mortality in Bayelsa State by 2018, it is important to invest more in women education and sensitization as well as improve medical facilities in Hospitals both in rural and urban region. The study provides important information on community perception on maternal health services in rural area in Bayelsa State. Naïve Bayes classification and to predict probability of Hypertensive disease (Preeclampsia and Gestational) and Bayesian maternal estimates of Maternal Mortality Rate was achieved.

\section{References}

Akinyemi, A. I. (2018) "Demographic dynamics and development in Nigeria". African Population Studies. 27: 239-248 - via ProQuest.

Arvind, S. \& Gupta, P.C. (2012). Predicting the Number of Blood Donors through their Age and Blood Group by using Data Mining Tooll International Journal of Communication and Computer Technologies Volume 01 - No.6, Issue: 02 September.

Elias, L. (2012). Hiv Status Predictive Modeling Using Data Mining Technology: predicting HIV status. Addis Ababa University: LAP LAMBERT Academic

Gandhi M and Singh S. N. (2015). Predictions in Heart Disease Using Techniques of Data Mining. International Conference on Futuristic trend in Computational Analysis and Knowledge Management (ABLAZE)

Graham, W., Ahmed, S., Stanton, C., Abou-Zahr, C., \& Campbell, O. (2008). Measuring maternal mortality: An overview of opportunities and options for developing countries. BMC Medicine, 6(1):12.

Han, J. \& Kamber, M. (2006). Data Mining: Concepts and Techniques, (2nd ed.). Amsterdam: Morgan Kaufmann

Hand, D., Heikki M., H., \& Smyth P. (2011). Principles of Data Mining. Cambridge: MIT Press

Hill, K, El Arifeen S, Koenig M, Al-Sabir A, Jamil K, \& Raggers H: (2006). How should we measure maternal mortality in the developing world? A comparison of household deaths and sibling history approaches. Bulletin of the World Health Organization, 84:173-180.

Jennet, P., Yeo, M., Scott, R., Hebert, M., \& Teo, W. (2015). Delivery of rural and remote health care via a broadband Internet Protocol network - views of potential users. Journal of Telemedicine and Telecare, 11(8), 419-424.

Khan, KS, Wojdyla, D, Say, L, Gülmezoglu, AM, (2006). WHO analysis systematic review. The Lancet, 367(9516):1066-1074.

National Bureau of statistics, Nigeria (2010). GeoHive - Nigeria Population Statistics, www.xist.org

Pitterson, L (2010). Making maternal mortality in Nigeria compelling enough. Media Global voice of the global south. www.media global.com.

Shegaw, A. (2012). Application of data mining technology to predict child mortality $\quad$ patterns: $\quad$ the case BRHP, MSc. Thesis, Addis Ababa University, Ethiopia.

Witten, I. H. \& Frank E. (2005). Data Mining: Practical Machine Learning Tools and Techniques, ( 2nd ed.). Amsterdam: Morgan Kaufmann. 